\title{
Group Status Drives Majority and Minority Integration Preferences
}

Psychological Science $\mathrm{XX}(\mathrm{X}) \mathrm{I}-6$

(c) The Author(s) 2011 Reprints and permission: sagepub.com/journalsPermissions.nav DOI: $10.1177 / 095679761$ | 423547 http://pss.sagepub.com

(\$) SAGE

\author{
Eric Hehman', Samuel L. Gaertner', John F. Dovidio², \\ Eric W. Mania ${ }^{3}$, Rita Guerra ${ }^{4}$, David C.Wilson ${ }^{5}$, and Brian M. Friel ${ }^{6}$ \\ 'Department of Psychology, University of Delaware; ${ }^{2}$ Department of Psychology, Yale University; \\ ${ }^{3}$ Department of Psychology, Quinsigamond Community College; ${ }^{4}$ Centro de Investigação e Intervenção Social, \\ Lisbon University Institute; ${ }^{5}$ Department of Political Science and International Relations, University of Delaware; \\ and ${ }^{6}$ Department of Psychology, Delaware State University
}

\begin{abstract}
This research examined preferences for national- and campus-level assimilative and pluralistic policies among Black and White students under different contexts, as majority- and minority-group members. We targeted attitudes at two universities, one where $85 \%$ of the student body is White, and another where $76 \%$ of students are Black. The results revealed that when a group constituted the majority, its members generally preferred assimilationist policies, and when a group constituted the minority, its members generally preferred pluralistic policies. The results support a functional perspective: Both majority and minority groups seek to protect and enhance their collective identities.
\end{abstract}

\section{Keywords}

immigration, intergroup dynamics, sociocultural factors, racial and ethnic attitudes and relations, minority groups

Received 3/29/II; Revision accepted 8/I9/II

As societies grow more diverse, developing peaceful methods of integration is increasingly important. The two most prominent integration ideologies are assimilation, according to which immigrants should be absorbed into the dominant society while relinquishing their original group culture, and pluralism, according to which immigrants should retain cultural distinctiveness while simultaneously identifying with the dominant culture (Berry, 2001). In general, members of host nations prefer assimilation, and members of immigrant groups favor pluralism (Pfafferott \& Brown, 2006; Verkuyten \& Yildiz, 2006; Zagefka \& Brown, 2002). Although research on differing group-integration preferences has focused on host and immigrant cultures, similar differences occur between Whites and Blacks in the United States (Ryan, Hunt, Weible, Peterson, \& Casas, 2007; Wolsko, Park, Judd, \& Wittenbrink, 2000 ), though each group has contributed historically to the development of the nation. Whites generally prefer assimilation, whereas Blacks, like immigrant groups, prefer pluralism (Dovidio, Gaertner, \& Kafati, 2000; Plaut, Thomas, \& Goren, 2009). These parallels in preference for assimilation or pluralism suggest that preferences for different integration ideologies may be rooted in strategic considerations serving to satisfy group-based needs (Dovidio, Gaertner, \& Saguy, 2009). The research reported here investigated how group preferences for these ideologies fluctuate as a function of groupbased concerns.
Building on social identity theory (Tajfel \& Turner, 1979), we posit that integration preferences may stem from motivations to perpetuate the group's values and distinctiveness from other groups. Assimilation allows the majority group to maintain the dominance of its values, thereby maintaining its positive social identity (Dovidio et al., 2009). Yet for a minority group, pluralism maximally enhances social identity by fostering positive distinctiveness from the dominant culture while establishing the legitimacy of this identity (Brewer, 1991; Scheepers, Spears, Doosje, \& Manstead, 2006).

Several studies have obtained results consistent with this proposed functional fluidity of integration preferences. Group preferences may shift as a function of social context (Schmitt, Branscombe, \& Kappen, 2003), and groups endorse culture maintenance more when an intergroup context is salient than when an intragroup context salient (Verkuyten \& de Wolf, 2002). Verkuyten and Yildiz (2006) found that Turkish and Kurdish immigrants living in The Netherlands and sharing minority status equally supported local minority rights. However, when these immigrants answered questions regarding minority rights in Turkey (where Turks constitute the majority

\footnotetext{
Corresponding Author:

Eric Hehman, Department of Psychology, University of Delaware, Newark, DE 19716

E-mail:ehehman@udel.edu
} 
but Kurds remain a minority), Turks endorsed minority rights less than Kurds did.

We argue that integration ideologies of Blacks and Whites in the United States are functional and therefore vary according to group-based needs in a given context. To the extent that integration preferences address the functional needs of the group, members shift their preferences systematically, depending on which ideology is most beneficial.

Adopting a functional perspective to understand why majorityand minority-group members endorse different integration preferences, we extended previous work by examining nonimmigrant majority- and minority-group members in multiple contexts. We examined integration preferences of students at two universities located only 42 miles apart: Delaware State University, a primarily Black school (76\% Black), and the University of Delaware, a primarily White institution ( $85 \%$ White).

We acknowledge that students at each university have deliberately chosen the institution they attend and are obviously not randomly assigned to their school condition. Nevertheless, the proximity and histories of these two state institutions offer a unique opportunity to examine the independent effects of local- and national-level majority and minority status on integration preferences. To explore the potential role of basic differences in orientations between the two schools, we assessed assimilation and pluralism preferences at both the national level, a context in which Whites are the majority and Blacks the minority regardless of the university attended, and the campus level, where the majority and minority status of Whites and Blacks depends on the specific university setting. Evidence that students of a given race exhibit different national-level integration preferences at the two universities would indicate a potential participant selection bias. However, a pattern in which White students at both universities and Black students at both universities show different preferences at the national level than at the campus level would demonstrate that preferences vary with the setting, which would be consistent with a functional perspective.

Thus, we hypothesized that in regard to national issues, White students at both universities would advocate assimilation more than Black students, whereas Blacks would endorse pluralism more than Whites. For campus issues, however, we predicted that each ethnic group would support assimilation more when it constituted the majority group (Whites at the University of Delaware, Blacks at Delaware State University) than when it constituted the minority group (Whites at Delaware State University, Blacks at the University of Delaware). Similarly, we predicted that the minority groups would endorse pluralism more strongly than the majority groups.

\section{Method}

\section{Participants}

A total of 480 students ( 350 female, 130 male) participated in this study. The subsample at the University of Delaware, a primarily White institution, included 209 Whites and 141 Blacks (mean age $=19.33$ years, $S D=1.15$ ). The subsample at Delaware State University, a primarily Black institution, included 29 Whites and 101 Blacks (mean age $=21.14$ years, $S D=4.76)$.

\section{Procedure}

Participants, who were recruited via e-mail and by research assistants at each campus, completed an online survey including our items of interest and a variety of demographic questions. Upon completing the survey, participants were paid $\$ 15.00$.

Survey items were intended to assess participants' endorsement of assimilation and pluralism at both the national and the campus level. Because of the distinct issues in national and campus contexts, assimilation and pluralism items differed in content depending on whether they addressed national or campus issues. Items were adapted from and inspired by previous research (Berry \& Kalin, 1995; Dovidio et al., 2000; Ryan et al., 2007). Participants indicated how much they agreed or disagreed with each statement on a scale from 1, strongly disagree, to 7, strongly agree. We conducted confirmatory factor analysis to verify that endorsements of national assimilation, national pluralism, campus assimilation, and campus pluralism were distinct factors. One-, two-, and four-factor models were estimated from the 28 items. Factor loadings clearly suggested that the four-factor model fit the data best, $\chi^{2}(344)=1,074.6, p<.001$; root mean square error of approximation $=.067$; comparative fit index $=.85$; relative fit index $=.78$; normed fit index $=.80{ }^{1}$ These factors (see Table 1) reflected endorsement of assimilationist national policies ( 8 items; $\alpha=.81$ ), pluralistic national policies (4 items; $\alpha=.81$ ), assimilationist campus policies ( 9 items; $\alpha=.82$ ), and pluralistic campus policies ( 7 items; $\alpha=$ $.85)$. For each factor, item scores were averaged to create a factor value; higher values reflect stronger support for the policies addressed by a given factor.

It would have been uninformative and potentially misleading to compare the mean level of endorsement across the four scales because content differed across the scales, and the level of endorsement was presumably influenced by the specific questions asked. For instance, scores for the endorsement of national assimilation were lower than scores for all other scales, across all groups. Therefore, we computed $z$ scores for each scale by normalizing across all participants simultaneously and then conducted analyses on the $z$ scores. ${ }^{2}$ After each main analysis, we present the results of a supplementary analysis of covariance controlling for the background variables of political conservatism, age, and parental education.

\section{Results}

We hypothesized that (a) in a national context, regardless of university affiliation, Whites would show a greater preference for assimilation than would Blacks, and Blacks would exhibit 
Table I. Items in Each Scale and Their Factor Loadings

\begin{tabular}{|c|c|}
\hline Scale and item & Loading \\
\hline \multicolumn{2}{|l|}{ National assimilation } \\
\hline If people want to succeed in the USA, they should adopt strictly American values. & 1.00 \\
\hline $\begin{array}{l}\text { In the USA, there is no point emphasizing our different racial identities when we are all just } \\
\text { Americans. }\end{array}$ & .99 \\
\hline To be a good American, it is best for people to de-emphasize their racial identities. & .94 \\
\hline $\begin{array}{l}\text { All children in this country should be taught to adopt the mainstream American values from } \\
\text { an early age. }\end{array}$ & .91 \\
\hline We should have a single official language in this country for all citizens: English. & .87 \\
\hline In the USA we should only celebrate American values, traditions and holidays. & .84 \\
\hline $\begin{array}{l}\text { In the USA, we should have one Miss America for all Americans, rather than a Miss America } \\
\text { for each racial group. }\end{array}$ & .59 \\
\hline $\begin{array}{l}\text { In the United States the government should devote more funds to common benefits for all } \\
\text { citizens rather than targeting some programs for specific racial groups. }\end{array}$ & .54 \\
\hline \multicolumn{2}{|l|}{ National pluralism } \\
\hline $\begin{array}{l}\text { We must appreciate the unique characteristics of each racial group in order to have a } \\
\text { cooperative society in the USA. }\end{array}$ & 1.00 \\
\hline What makes the USA strong is that we are a mixture of different races and cultures. & .99 \\
\hline $\begin{array}{l}\text { The United States government should devote more funds to multicultural exhibits in national } \\
\text { museums in Washington, DC. }\end{array}$ & .95 \\
\hline $\begin{array}{l}\text { If we want to create a harmonious society in the USA, we must recognize that each racial } \\
\text { group has the right to maintain its own unique traditions. }\end{array}$ & .87 \\
\hline \multicolumn{2}{|l|}{ Campus assimilation } \\
\hline $\begin{array}{l}\text { There is no point emphasizing our different racial identities when we are all just students at } \\
\text { this university. }\end{array}$ & 1.00 \\
\hline $\begin{array}{l}\text { At this university, there should be a single center on campus for all students, rather than } \\
\text { separate cultural centers for students of different racial groups. }\end{array}$ & .98 \\
\hline $\begin{array}{l}\text { There should be a single student government on this campus, rather than separate ones } \\
\text { for different racial groups. }\end{array}$ & .91 \\
\hline $\begin{array}{l}\text { Applicants to this university should be treated without consideration of their racial } \\
\text { backgrounds. }\end{array}$ & .75 \\
\hline $\begin{array}{l}\text { This university should devote more funds to common activities for all students, rather than } \\
\text { targeting funds for particular racial groups. }\end{array}$ & .74 \\
\hline $\begin{array}{l}\text { I prefer to regard all students at this university simply as students rather than as Black } \\
\text { students or White students. }\end{array}$ & .65 \\
\hline At this university, the established student government can serve all the students well. & .57 \\
\hline $\begin{array}{l}\text { At this university, students from different racial groups should all have the same set of core } \\
\text { values. }\end{array}$ & .53 \\
\hline This university should treat students from different racial groups the same in all respects. & .50 \\
\hline \multicolumn{2}{|l|}{ Campus pluralism } \\
\hline $\begin{array}{l}\text { At this university, admissions should consider the value that different racial groups bring to } \\
\text { the university. }\end{array}$ & 1.00 \\
\hline $\begin{array}{l}\text { At this university, it is essential to ensure that there is diversity in terms of racial group } \\
\text { membership among the students, faculty and staff. }\end{array}$ & .90 \\
\hline This university should devote more funds to multicultural activities on campus. & .85 \\
\hline $\begin{array}{l}\text { This university should require a course on the unique histories of the different racial groups } \\
\text { that compose our student body. }\end{array}$ & .85 \\
\hline This university should respect the unique situations of students from different racial groups. & .78 \\
\hline $\begin{array}{l}\text { This university should promote the celebration of traditions of the different racial groups on } \\
\text { campus. }\end{array}$ & .78 \\
\hline In classes at this university, all students benefit from the contributions of different racial groups. & .70 \\
\hline
\end{tabular}

a stronger preference for pluralism than would Whites, and (b) in a campus context, preferences for assimilation and pluralism would differ as a function of group majority or minority status at each university. Consistent with our hypothesis, a 2 (race: Black, White) $\times 2$ (university: primarily White, primarily Black) $\times 2$ (ideology: assimilation, pluralism) $\times 2$ (domain: 
National Assimilation

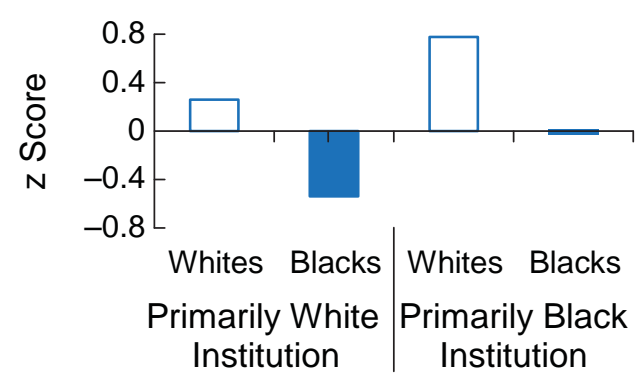

National Pluralism

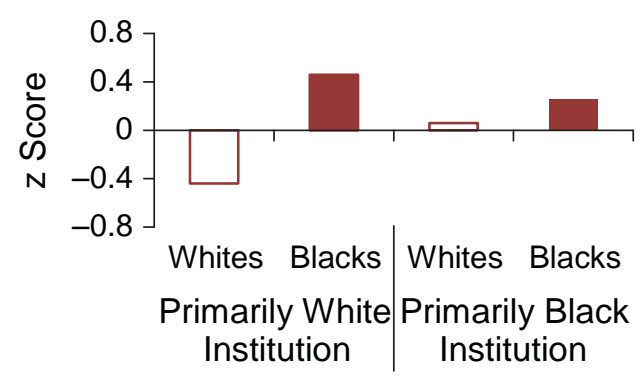

Campus Assimilation

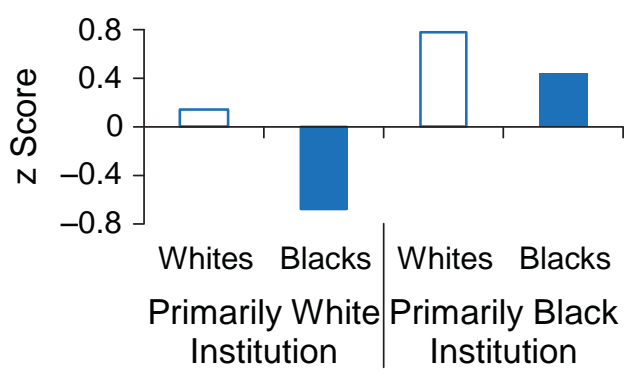

Campus Pluralism

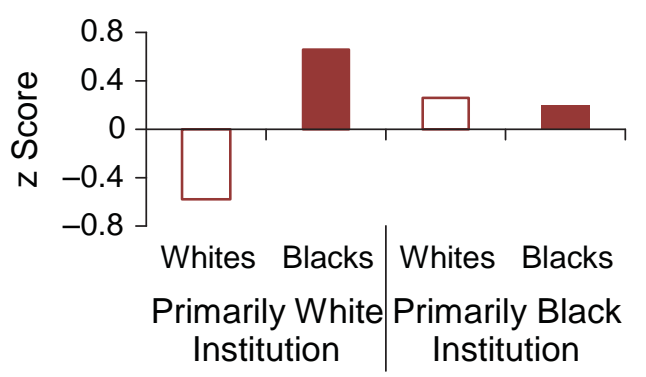

Fig. I. Mean endorsement (z scores) of assimilation and pluralism at the national and campus levels among Black and White participants at each university.

national, campus) mixed-model analysis of variance (ANOVA) with repeated measures on the last two factors revealed a significant four-way interaction, $F(1,476)=10.60, p=.001$, $\eta_{\mathrm{p}}{ }^{2}=.02$ (see Fig. 1; for raw-score means, see Table 2). This interaction remained significant even when controlling for political conservatism, age, and parental education, $F(1$, 473) $=9.91, p=.002, \eta_{p}^{2}=.02$.

\section{National level}

Consistent with our hypotheses for the national domain, a 2 (race) $\times 2$ (university) $\times 2$ (ideology) ANOVA revealed the

Table 2. Mean Raw Scores for Endorsement of Assimilation and Pluralism at the National and Campus Levels, by Race and University

\begin{tabular}{lcc}
\hline Measure and racial group & $\begin{array}{c}\text { Primarily White } \\
\text { institution }\end{array}$ & $\begin{array}{c}\text { Primarily Black } \\
\text { institution }\end{array}$ \\
\hline National assimilation & 4.15 & 3.83 \\
$\quad$ Whites & 3.24 & 3.24 \\
$\quad$ Blacks & & \\
National pluralism & 3.24 & $5.5 \mathrm{I}$ \\
$\quad$ Whites & 5.91 & 5.72 \\
$\quad$ Blacks & & \\
Campus assimilation & 5.20 & 5.89 \\
$\quad$ Whites & 4.33 & 5.52 \\
$\quad$ Blacks & & \\
Campus pluralism & 4.42 & 5.38 \\
$\quad$ Whites & 5.81 & 5.31 \\
$\quad$ Blacks & & \\
\hline
\end{tabular}

predicted Race $\times$ Ideology interaction, $F(1,476)=58.55, p<$ $.001, \eta_{\mathrm{p}}{ }^{2}=.11$. As anticipated, Whites $(M=0.518, S D=0.88)$ endorsed national assimilation more than Blacks $(M=-0.272$, $S D=1.01), F(1,476)=51.94, p<.001, \eta_{\mathrm{p}}{ }^{2}=.10$. Also, Blacks $(M=0.359, S D=0.90)$ endorsed national pluralism more than Whites $(M=-0.272, S D=0.96), F(1,476)=25.73, p<.001$, $\eta_{\mathrm{p}}{ }^{2}=.05$. In addition, there was an unexpected marginally significant Race $\times$ University $\times$ Ideology interaction, $F(1,476)=$ $3.81, p=.051, \eta_{\mathrm{p}}{ }^{2}=.01$. As illustrated in the left-hand panels of Figure 1, the basic pattern of Whites showing a greater preference for national assimilation and Blacks showing a greater preference for national pluralism was found for both campuses, but this Race $\times$ Ideology interaction was stronger for students at the primarily White institution, $F(1,348)=105.58, p<.001$, $\eta_{\mathrm{p}}{ }^{2}=.23$, than for those at the primarily Black institution, $F(1$, $128)=11.36, p<.001, \eta_{\mathrm{p}}^{2}=.08$. The analysis of covariance also showed the expected Race $\times$ Ideology interaction, $F(1,473)=$ $55.82, p<.001, \eta_{\mathrm{p}}{ }^{2}=.11$, but the Race $\times$ University $\times$ Ideology interaction was nonsignificant $(p=.102)$; this result suggests that the three-way interaction observed for national preferences should be interpreted cautiously.

\section{Campus level}

As predicted, for the campus domain, Whites' and Blacks' support for the different integration ideologies was moderated by university setting: The Race $\times$ University $\times$ Ideology interaction was significant, $F(1,476)=36.73, p<.001, \eta_{\mathrm{p}}{ }^{2}=.07$. This interaction remained significant after controlling for background variables, $F(1,473)=30.12, p<.001, \eta_{p}{ }^{2}=.06$. 
In an ANOVA focusing on campus assimilation, a Race $\times$ University interaction was obtained, $F(1,476)=5.09, p=$ $.025, \eta_{\mathrm{p}}{ }^{2}=.01$. As expected, Blacks indicated more support for assimilation on campus when they were the majority group $(M=0.435, S D=0.80)$ than when they were the minority group $(M=-0.663, S D=1.08), F(1,476)=90.60, p<.001$, $\eta_{\mathrm{p}}{ }^{2}=.16$. Whites at the primarily Black institution unexpectedly showed more support for campus assimilation $(M=$ $0.775, S D=0.65)$ than did those at the primarily White institution $(M=0.140, S D=0.80), F(1,476)=13.12, p<.001, \eta_{\mathrm{p}}{ }^{2}=$ .03 , although the difference between universities was smaller for Whites than for Blacks, $F(1,476)=5.09, p=.025, \eta_{\mathrm{p}}{ }^{2}=$ .01 . The Race $\times$ University interaction for campus assimilation remained significant when background variables were controlled, $F(1,473)=4.09, p=.044, \eta_{\mathrm{p}}{ }^{2}=.01$.

The Race $\times$ University interaction was also significant for endorsement of campus pluralism, $F(1,476)=41.44, p<.001$, $\eta_{\mathrm{p}}{ }^{2}=.08$, and reflected the hypothesized pattern. Blacks reported more support for pluralism on campus at the primarily White institution $(M=0.654, S D=0.68)$ than at the primarily Black institution $(M=0.213, S D=0.79), F(1,476)=15.96$, $p<.001, \eta_{\mathrm{p}}^{2}=.03$. Additionally, Whites at the primarily Black institution showed more support for pluralism $(M=0.272$, $S D=0.99)$ than did Whites at the primarily White institution $(M=-0.580, S D=0.95), F(1,476)=25.78, p<.001, \eta_{\mathrm{p}}^{2}=$ .05. The analysis of covariance controlling for background variables also revealed the Race $\times$ University interaction for endorsement of campus pluralism, $F(1,473)=33.73, p<.001$, $\eta_{\mathrm{p}}^{2}=.07$.

\section{Discussion}

The overall pattern of results supports our hypotheses regarding a functional interpretation of group-integration preferences (Dovidio et al., 2009). At the national level, where Whites constitute the majority and Blacks the minority, Whites generally endorsed assimilation more than Blacks, and Blacks generally endorsed pluralism more than Whites. However, at the university level, where the majority-minority status of Whites and Blacks varied, both minority groups, regardless of race, endorsed pluralism more when they were in the minority than when they were in the majority.

The difference between results at the national and campus levels indicates that the differences between Blacks' and Whites' endorsement of the two ideologies were related to group status within each context, rather than to systematic differences between the students who chose to attend the two universities. Had the results been due to ideological differences between students attending a primarily White institution and those attending a primarily Black institution, students of each race at each university would have displayed similar preferences at the national and campus levels. Thus, selection bias does not readily account for our results.

Previous experimental work has examined the unique influences of group size, power (i.e., control over other people and their resources), and status (i.e., the social value of group membership) on intergroup relations (Boldry \& Gaertner, 2006; Gonzalez \& Brown, 2006). These dimensions frequently covary in naturalistic conditions, and our study cannot definitively determine which specific dimensions might have driven the effects we observed. The obtained support for the functional perspective, however, suggests that in addition to possible influences of these dimensions, other contextually related factors affecting the needs of particular groups may systematically determine preferences. For example, in contrast to the United States and United Kingdom, Portugal began to experience significant immigration only 40 years ago. Perhaps because of these immigrants' insecurity regarding their status, Guerra et al. (2010) found a pattern opposite that typically found with majority and minority groups: During interactions with majority-group members, Portuguese minorities demonstrated less in-group favoritism when interactions were structured to appear assimilative (e.g., integrated seating, common group name) than when they were structured to appear pluralistic (e.g., segregated seating, separate group names). Thus, groups may systematically adopt differing integration preferences to meet their needs in specific situations and cultural contexts, and integration preferences may be more complex than previously suspected.

Additionally, group preferences for pluralism or assimilation may be increased under other conditions in which preferences are more immediately functional. Minority-group endorsement of pluralism might increase the group's solidarity in pursuit of collective action (Hornsey \& Hogg, 2000), whereas endorsement of assimilation might serve a protective function for the majority, undermining minority attempts at collective action. Future work might examine contexts in which strategic considerations influence preferences for different integration ideologies.

Although our results implicate group status as the potent factor shaping preferences for assimilation or pluralism, other factors did exert some influence on campus-level preferences. In particular, Whites' status as the majority or minority at their university had less of an effect on their endorsement of assimilation, their generally preferred ideology, than on their preference for pluralism. Similarly, Blacks' status as the majority or minority at their university had less of an effect on their preference for pluralism, their generally preferred ideology, than on their preference for assimilation. Thus, although contextual group status exerts a systematic influence, Whites and Blacks do not entirely abandon the general preferences that may operate in other facets of their lives.

Our unanticipated finding that Whites at the primarily Black institution still showed a greater preference for assimilation over pluralism with regard to campus issues may partly stem from the aggregate of their on- and off-campus experiences. Although this effect persisted when we statistically controlled for a range of background variables, other factors may play a role. In particular, a notable percentage $(18 \%)$ of the White students at the primarily Black institution attend college 
part-time. To the extent that these students spend a substantial proportion of their time in working environments outside of college, these experiences may dilute the impact of their minority status at college. Nevertheless, being a minority at college did have an effect on White students' preferences; as hypothesized, Whites at the primarily Black institution had stronger preferences for campus pluralism than did Whites at the primarily White institution. Future research might further consider the factors that may either increase or decrease group members' propensity to shift their integration preferences.

Overall, our study has extended previous work on preferences of immigrant and host community groups (Verkuyten \& Yildiz, 2006) by examining group preferences among nonimmigrant groups-U.S. Blacks and Whites, who share common history in the origins of their nation - that simultaneously constitute both a majority and a minority. Our findings show that integration preferences vary as a function of group context and goals. Understanding that these preferences are not stable and determining when, why, and how they shift can help illuminate the dynamics of intergroup interactions and relations more generally, making it possible to identify when conflict may be exacerbated and when optimal opportunities for cooperation may occur.

\section{Declaration of Conflicting Interests}

The authors declared that they had no conflicts of interest with respect to their authorship or the publication of this article.

\section{Funding}

This research was supported by a National Science Foundation Grant (BCS 0613218) to Samuel L. Gaertner and John F. Dovidio.

\section{Notes}

1. The four-factor model fit the data significantly better than a twofactor model with factors reflecting assimilation and pluralism, $\Delta \chi^{2}(5)=529, p<.001$.

2. Although the analyses involved standardized scores, we include the raw scores in the caption for Figure 1.

\section{References}

Berry, J. W. (2001). A psychology of immigration. Journal of Social Issues, 57, 615-631.

Berry, J. W., \& Kalin, R. (1995). Multicultural and ethnic attitudes in Canada: An overview of the 1991 national survey. Canadian Journal of Behavioural Science, 27, 301-320.

Boldry, J. G., \& Gaertner, L. (2006). Separating status from power as an antecedent of intergroup perception. Group Processes \& Intergroup Relations, 9, 377-400.

Brewer, M. B. (1991). The social self: On being the same and different at the same time. Personality and Social Psychology Bulletin, 17, 475-482.

Dovidio, J. F., Gaertner, S. L., \& Kafati, G. (2000). Group identity and intergroup relations: The common in-group identity model. In S. R. Thye, E. J. Lawler, M. W. Macy, \& H. A. Walker (Eds.),
Advances in group processes (Vol. 17, pp. 1-34). Stamford, CT: JAI Press.

Dovidio, J. F., Gaertner, S. L., \& Saguy, T. (2009). Commonality and the complexity of "we": Social attitudes and social change. Personality and Social Psychology Review, 13, 3-20.

Gonzalez, R., \& Brown, R. (2006). Dual identities and intergroup contact: Group status and size moderate the generalization of positive attitude change. Journal of Experimental Social Psychology, 42, 753-767.

Guerra, R., Rebelo, M., Monteiro, M. B., Riek, B. M., Mania, E. W., Gaertner, S. L., \& Dovidio, J. F. (2010). How should intergroup contact be structured to reduce bias among majority and minority group children? Group Processes \& Intergroup Relations, 13, 445-460.

Hornsey, M. J., \& Hogg, M. A. (2000). Assimilation and diversity: An integrative model of subgroup relations. Personality and Social Psychology Review, 4, 143-156.

Pfafferott, I., \& Brown, R. (2006). Acculturation preferences of majority and minority adolescents in Germany in the context of society and family. International Journal of Intercultural Relations, 30, 703-717.

Plaut, V. C., Thomas, K. M., \& Goren, M. J. (2009). Is multiculturalism or color blindness better for minorities? Psychological Science, 20, 444-446.

Ryan, C. S., Hunt, J. S., Weible, J., Peterson, C. R., \& Casas, J. F. (2007). Multicultural and colorblind ideology, stereotypes, and ethnocentrism among Black and White Americans. Group Processes \& Intergroup Relations, 10, 617-637.

Scheepers, D., Spears, R., Doosje, B., \& Manstead, A. S. R. (2006). Diversity in in-group bias: Structural factors, situational features, and social functions. Journal of Personality and Social Psychology, 90, 944-960.

Schmitt, M. T., Branscombe, N. R., \& Kappen, D. M. (2003). Attitudes toward group-based inequality: Social dominance or social identity? British Journal of Social Psychology, 42, 161-186.

Tajfel, H., \& Turner, J. C. (1979). An integrative theory of intergroup conflict. In W. G. Austin \& S. Worchel (Eds.), The social psychology of intergroup relations (pp. 33-48). Monterey, CA: Brooks-Cole.

Verkuyten, M., \& de Wolf, A. (2002). Ethnic minority identity and group context: Self-descriptions, acculturation attitudes and group evaluations in an intra- and intergroup situation. European Journal of Social Psychology, 32, 781-800.

Verkuyten, M., \& Yildiz, A. A. (2006). The endorsement of minority rights: The role of group position, national context, and ideological beliefs. Political Psychology, 27, 527-548.

Wolsko, C., Park, B., Judd, C. M., \& Wittenbrink, B. (2000). Framing interethnic ideology: Effects of multicultural and color-blind perspectives on judgments of groups and individuals. Journal of Personality and Social Psychology, 78, 635-654.

Zagefka, H., \& Brown, R. (2002). The relationship between acculturation strategies, relative fit and intergroup relations: Immigrant-majority relations in Germany. European Journal of Social Psychology, 32, 171-188. 